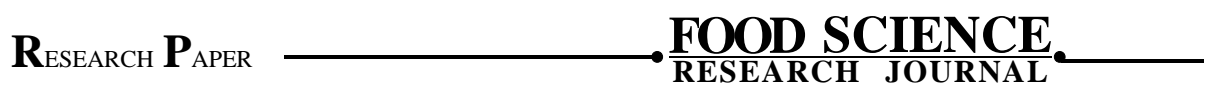

e ISSN-2230-9403 $\square$ Visit us :
www.researchjournal.co.in
Volume $8 \mid$ Issue $1 \mid$ April, 2017 | 29-34
DOI : $10.15740 / \mathrm{HAS} /$ FSRJ/8.1/29-34

\title{
An appraisement of the knowledge of rural Kashmiri women regarding consumption of foods and nutritional supplements during pregnancy
}

\author{
IfFAt GHANi AND RAJini DhingRa
}

\begin{abstract}
In prenatal nutrition, intake of adequate and balanced diet and also nutritional supplements are required for successful pregnancy outcomes. The aim of this study was to determine the knowledge of Kashmiri rural women, comprising of beneficiaries of ICDS centres belonging to district Budgam of Kashmir region. Nursing mothers (NM), Pregnant women (PW) and Mother of children beneficiaries (MCB age 6 months-3years) were included to assess and compare their awareness levels. A total of 600 women beneficiaries were randomly selected from four blocks of district Budgam (150 from each block).It was observed that majority of Kashmiri sample women were not fully aware about the importance of nutritional supplements during pregnancy. It was also found that a moderate percentage of sample women were well aware about importance of diet during pregnancy, but still some of the respondents perceived that normal diet with organ meat is a good choice during pregnancy. Further it was observed that the Kashmiri sample women believe in consuming foods like - dates (dry), almonds and apricots boiled with milk and also diluted milk to help in increasing the hemoglobin $(\mathrm{Hb})$ level of anemic women. However, the sample women perceived that sour foods and dry fruits (as such), nonvegetarian (particularly beef) should be avoided during pregnancy. The findings indicate that an effective implementation of nutritional educational programmes for women of childbearing age to educate pregnant women and proper explanation of instructions by doctor/health workers is needed tohelp improve the knowledge regarding dietary habits of rural women by providing proper and effective interventions in rural areas. To further increase compliance of pregnant women with iron supplementation, health workers/AWWs should establish a good health provider- patient relationship that can help in motivating the respondents.
\end{abstract}

Key Words : Pregnancy, Supplements, Knowledge, Diet

How to cite this article : Ghani, Iffat and Dhingra, Rajini (2017). An appraisement of the knowledge of rural Kashmiri women regarding consumption of foods and nutritional supplements during pregnancy. Food Sci. Res. J., 8(1): 29-34, DOI : 10.15740/HAS/ FSRJ/8.1/29-34.

\footnotetext{
Author for correspondence :

IFFAT GHANI, Krishi Vigyan Kendra (SKUAST-K), PULWAMA (J\&K) INDIA

Associate Authors' :

RAJINI DHINGRA, University of Jammu, JAMMU (J\&K) INDIA
} 